\title{
Self-Assembly of Amyloid-Beta and Its Piezoelectric Properties
}

\author{
Ivonne Rosales', Laura Salazar², Daniel Luna², Alicia Negrón², Igor Bdikin³, \\ Brian J. Rodriguez ${ }^{4}$, Alejandro Heredia ${ }^{2}$
}

\author{
${ }^{1}$ Departamento de Física y Química Teórica, Facultad de Química, Universidad Nacional Autónoma de México, Ciudad \\ Universitaria, Circuito Exterior S/N, Coyoacán, Mexico City, Mexico \\ ${ }^{2}$ Laboratorio de Evolución Química, Instituto de Ciencias Nucleares, Universidad Nacional Autónoma de México, Mexico City, \\ Mexico \\ ${ }^{3}$ Nanoengineering Research group, Centre for Mechanical Technology \& Automation, University of Aveiro, Aveiro, Portugal \\ ${ }^{4}$ School of Physics and Conway Institute of Biomolecular and Biomedical Research University College Dublin Belfield, Dublin, \\ Ireland \\ Email: ivonne.rosales.ch@gmail.com, brian.rodriguez@ucd.ie, aheredia@nucleares.unam.mx, bdikin@ua.pt
}

How to cite this paper: Rosales, I., Salazar, L., Luna, D., Negrón, A., Bdikin, I., Rodriguez, B.J. and Heredia, A. (2021) Self-Assembly of Amyloid-Beta and Its Piezoelectric Properties. American Journal of Molecular Biology, 11, 1-14.

https://doi.org/10.4236/ajmb.2021.111001

Received: October 12, 2020

Accepted: December 15, 2020

Published: December 18, 2020

Copyright (c) 2021 by author(s) and Scientific Research Publishing Inc. This work is licensed under the Creative Commons Attribution International License (CC BY 4.0).

http://creativecommons.org/licenses/by/4.0/

(c) (i) Open Access

\begin{abstract}
Investigating amyloid nanofibril self-assembly, with an emphasis on the electromechanical property of amyloid peptides, namely, piezoelectricity, may have several important implications: 1) the self-assembly process can hinder the biological stability and give rise to the formation of amyloid structures associated with neurodegenerative diseases; 2 ) investigations in this field may lead to an improved understanding of high-performance, functional biological nanomaterials, 3) new technologies could be established based on peptide self-assembly and the resultant functional properties, e.g., in the creation of a piezoelectric device formed with vertical diphenylalanine peptide tubes as a piezoelectric biosensor, and 4) new knowledge can be generated about neurodegenerative disorders, potentially yielding new therapies. Therefore, in this review, we will present the current investigations associated with self-assembly of amyloid-beta, the mechanisms that generate new structures, as well as theoretical calculations exploring the functionality of the structures under physiological pressure and electric field.
\end{abstract}

\section{Keywords}

Amyloid, Neurodegenerative Disorders, Self-Assembly, Piezoelectricity

\section{Introduction}

Neurodegenerative disorders such as Alzheimer's disease, Parkinson's disease, 
Huntington disease, and others [1] [2] are diseases with worldwide prevalence associated with the disruption of signaling pathways at the neuronal level and linked to the elderly population of countries with high longevity, Figure 1 . The interaction of amyloid fibril deposits with cellular components is said to be responsible for these disorders; since amyloids have an essential physiological role in lipid homeostasis. Modifications to the self-assembly properties or molecular stability of amyloids [3] can result in the formation of amyloid fibrils that completes the self-assembly process in the cell membrane [3] [4]. In the study of the cause of neurodegenerative disorders, several approaches can be established, such as assembling the amyloids with lipids, since other neuronal factors change with the presence of amyloids, as has been discovered for soluble fractions of lipids or potassium voltage-gated channels [5]; additional experiments showed a change in the aggregation of the amyloid molecules when interacting with other biomacromolecules. These observations, for instance, indirectly show that lipids and voltage-sensitive peptides modify the structural and aggregation properties of the amyloids. These prior studies required molecular biology methods, followed by complex physiology measurements. From our perspective, the formation and properties of those complex molecules might be controlled by the interaction with lipids and voltage-dependent peptides. Such assemblies may have some biofunctional role, especially if the possible interactions between voltage-gated channels and voltage-sensitive peptides are taken into account [6].

The presence of phenylalanine fragments is of vital importance for the self-assembly [7] since according to molecular modeling, dipole moments are detected in amyloid derivatives as diphenylalanine (FF) [8] suggesting that the three-dimensional ordering (self-assembly) might produce an electromechanical response as reported by Kholkin et al., [9] in nanotube-type auto-assemblies

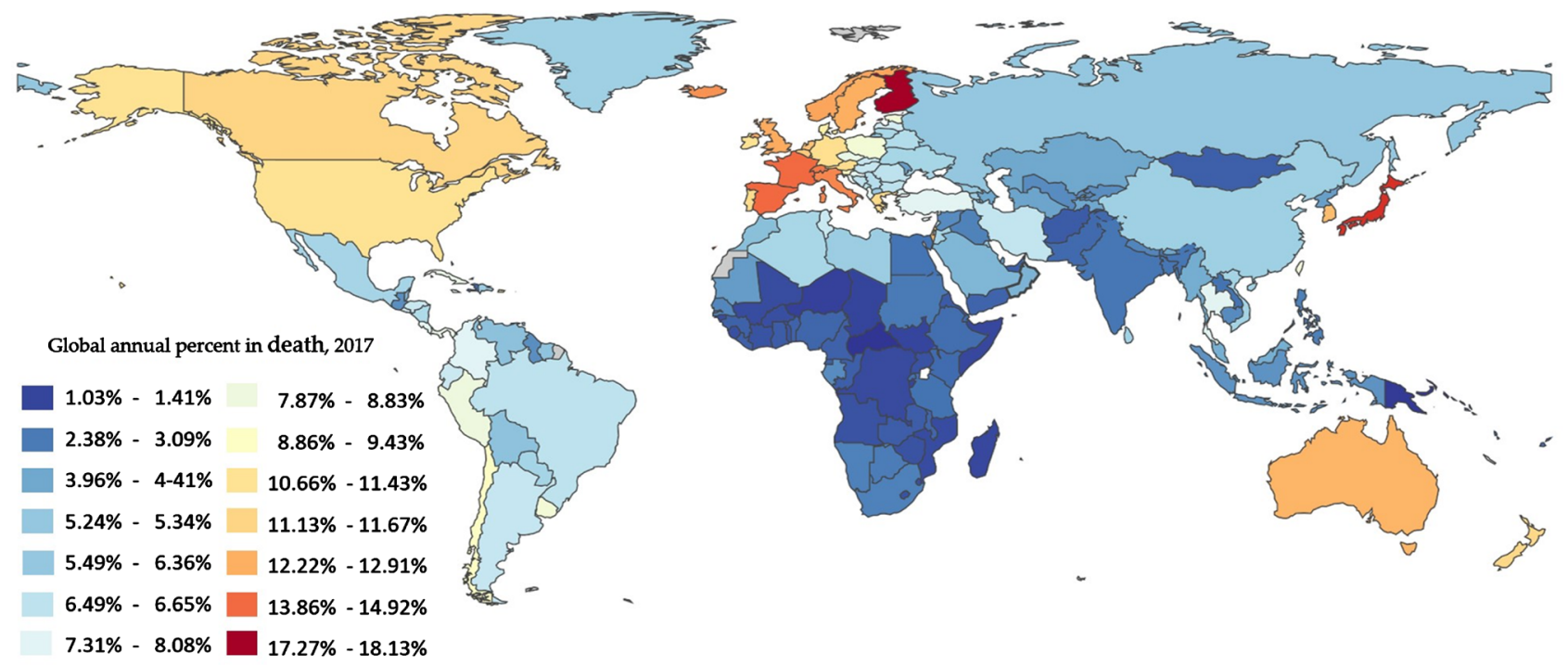

Figure 1. Distribution of annual percent of neurodegenerative diseases at the global level available until the year 2017, according to the Institute for Health Metrics and Evaluation (IHME). GBD Compare Data Visualization. Seattle, WA: IHME, University of Wash-ington, 2018. Available from http://vizhub.healthdata.org/gbd-compare (Accessed: December 9, 2019). 
with a high effective piezoelectric coefficient of at least $60 \mathrm{pm} / \mathrm{V}$. These electromechanical properties of macromolecular self-assemblies are of primary importance, for instance, in the synthesis of new organic ferroelectric, piezoelectric nanostructures fundamental to the creation of a new class of materials from biomedical up to electronic biocompatible "green" or "ecological" memory devices [10] [11], the understanding of which can serve as the basis to produce organic and organic-inorganic self-assembled micro and nanomaterials. In order to define the role of the external factors on the assembly of amyloids, it is necessary to study the electromechanical properties as tunable features in the amyloids.

\section{Self-Assembly}

Self-assembly is a common molecular-scale phenomenon found in the organic, inorganic, and hybrid matter, and is ubiquitous where the interplay of polar and non-polar local interactions coexists [12]. Piezoelectric properties in the self-assembly of organic molecules [9] is a fascinating process that has inspired recent molecular approaches to micro- and nanodevice design [13] as well as biomimetic approaches [14] to the design of drugs to target the formation of plaques associated with diseases like Alzheimer's [15] [16]. Self-assembly of peptides and greater control of functional morphogenesis is a complex process and likely self-assembly processes are strongly governed by biological and physicochemical factors [17]; therefore, understanding intrinsic and extrinsic factors on amyloid self-assembly is a vital step towards a promising route of exploiting self-assembled structures in nanotechnologies [18]. For example, the biological stability of some peptide domains under different thermal conditions and environments (i.e., vacuum) might also be found in amyloids.

At the present time, determining the exact role of each factor and the degree of integration of the different processes is difficult to achieve [19], but various targeted studies have suggested their importance. With the identification of active regions for self-assembly in the amyloid peptide (diphenylalanine "FF" region), new tubular organic structures have been successfully synthesized [17] [20] [21].

It should be noted that the role of the active regions was determined by in vitro experiments as one of the possible mechanisms responsible for the formation of amyloid in tissues, which leads to disease formation (Figure 2(a)). On the other hand, based on chemical and computational studies [8], it was determined that an important part of the stability of the self-assemblies originates in the pi-pi stacking of the hydrophobic FF regions [16] [22] and whose piezoelectric properties decrease according to a second-order polynomial function with temperature, accompanied by an irreversible phase transition towards another crystalline phase as reported by Heredia et al. [8] (Figure 2(b)). Self-assembly processes may lead to the formation of the well-known hierarchical structure of beta amyloids [23] and similar complex macromolecules [4]. Studying the self-assembly process is crucial to understand its mechanism since it may become 


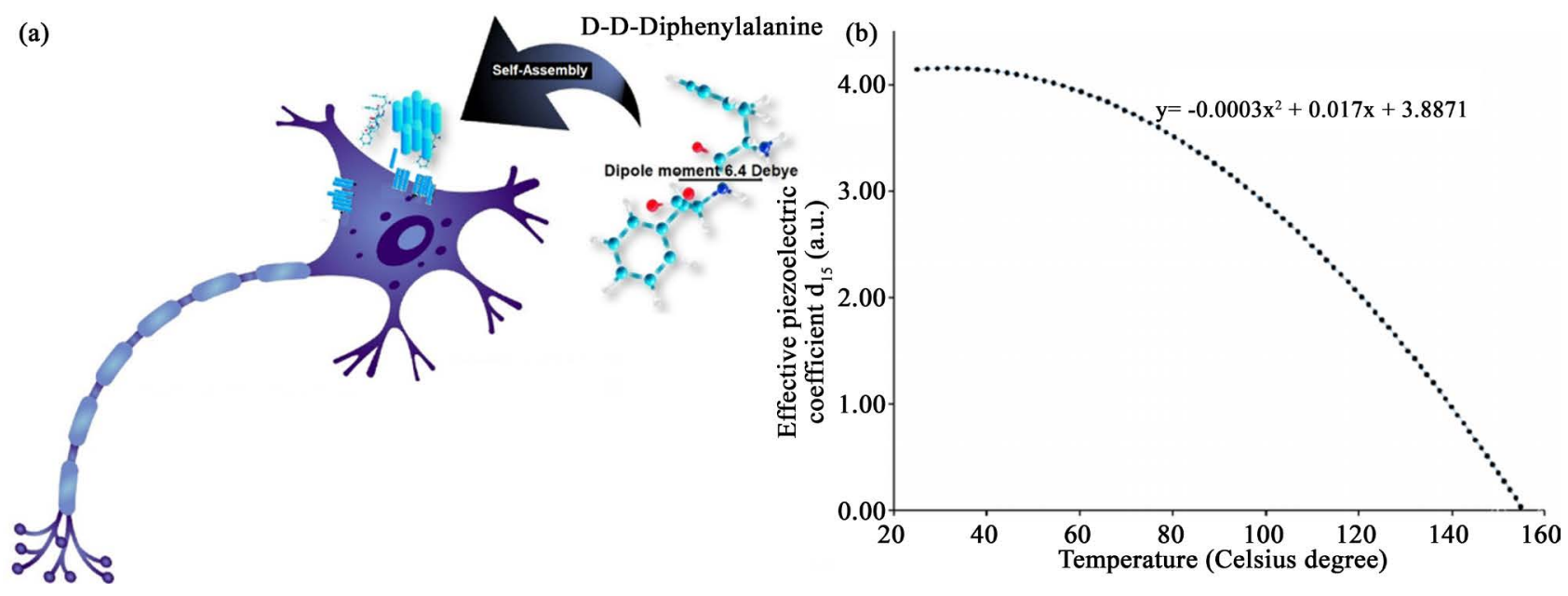

Figure 2. Self-assembly of diphenylalanine peptide might produce physiological changes in cells (a). Behavior of effective piezoelectric coefficient $d_{15}$ of diphenylalanine peptide nanotubes with respect to the temperature (b), according to the results reported by Heredia et al. in "Temperature driven phase transformation in self-assembled diphenylalanine peptide nanotubes".

possible to hinder the development of amyloid structures associated with diseases and to exploit the design of new technologies based on peptide self-assembly and the resultant functional properties, e.g., a piezoelectric device formed with vertical FF peptide tubes as a piezoelectric biosensor [13] [24], for this reason, the stability of the self-assemblies is discussed below.

The feasibility of self-assembly of some amyloid domains is of importance [17] [19] [25] [26] since the synthesis of a piezoelectric peptide-based device is plausible [9]. One of the most used domains is the $\mathrm{A} \beta-(1-40)$ region because it represents the most abundant $\mathrm{A} \beta$ isoform in the brain [27] and the topographical features of $\mathrm{A} \beta-(1-40)$ fibrils are thought to play an important role in neurodegenerative disorders and other diseases [28] [29]; works about it have shown that the production rates of $\mathrm{A} \beta-(1-40)$ and $\mathrm{A} \beta-(1-42)$ isomorphs are the same or in a higher proportion, and that $\mathrm{A} \beta-(1-42)$ fragment in neurodegenerative disorders is much more prone to form fibrils [2] [30]. Although initially, the preference for amyloid regions in self-assembly has been chosen based on the ease of self-assembly, in some works based on the optimization of piezoelectric organic structures, revealed a clear effect on the macroscopic amyloids when mixed with other molecules [29] [31] [32].

\section{Self-Assembly in Water}

In the past century, tubular $A \beta$ structures were studied by Max Perutz [29] who established that encased water molecules should be of main importance for their biological activity. Indeed, water molecules are responsible for the electromechanical behavior in some amyloid structures [33] [34]. Initial experiments using atomic force microscopy (AFM) of different biostructures in liquid [35] and air [36] environments on different substrates [37] described the different self-assemblies observed, including peptides. Solutions of the amyloid peptide are commonly dissolved in fluorinated alcohol (1,1,1,3,3,3-hexafluoro-2-propanol) and then self- 
assembled in another solvent [38] [39] to form fibers with around $10 \mathrm{~nm}$ diameter depending on the $\mathrm{pH}, v \cdot g r$, distilled water (Milli-Q) to obtain fibrils (PBS, $\left.\mathrm{pH} 7.4,37^{\circ} \mathrm{C}\right)[40]$.

Organic molecular self-assembly in water or at solid surfaces is a well-known phenomenon governed by the interplay between molecule-molecule and molecule-substrate interactions, which can be tailored by varying molecular building blocks, ion strengths, surface chemistry, and structure, as well as substrate temperature [12] [14] [38]. Indeed, one of the questions in the study of self-assembled organics is the role that water molecules play at the surface or inside self-assembled structures [29], being a precedent in these studies is the identification of electromechanical properties in diphenylalanine nanotubes [9].

The self-assembly of amyloid nanofibril in aqueous solutions has been investigated in detail as a function of ion concentration, temperature, and lipid and amino acid incorporation to determine the mechanism of electromechanical coupling in organic macromolecular assemblies [41] [42] and the pathway to optimize and exploit this functional property of inherently biocompatible materials, like in collagen-apatite at the nanoscale [43]. Organic supramolecular structures are easily fibrillated from water solutions to produce self-assembled organic piezoelectric nanostructures. Controlled self-assembly conditions e.g., temperature, $\mathrm{pH}$ [26], have been previously been used to describe the physicochemical effect on the fibril nanostructure by mean infrared spectroscopy (FTIR) [44]. That is important since in the modality of Attenuated Total Reflectance (ATR-FTIR) FTIR is applied to know the evolution in the secondary structure of the molecules as a method described by Dave et al., using the amide I band position [45]. The presence of amide II and I FTIR might substantiate an oligomerization process of prebiotic relevance. However, it also is important to consider structural factors in the role of the origins of piezo- and ferroelectricity. These electromechanical and electrical properties studied through nanoscale measurements are required to develop an accurate biophysical description, that can be achieved by a high resolution technique as piezoresponse force microscopy, PFM, in which a conducting probe scan the sample surface that allows to determine the morphology and nanostructure of the self-assemblies. PFM is a powerful tool for studying piezoelectric and ferroelectric phenomena at the micro- and nanoscale levels. In this method, a sharp conductive scanning probe microscopy tip in contact with the surface is periodically biased, and bias-induced surface displacements are translated into the mechanical motion of the tip, which is measured using the AFM electronics and an external lock-in amplifier. In PFM imaging, both out-of-plane (OOP) and in-plane (IP) displacements can thus be monitored to get insight into the nanoscale piezoelectric and ferroelectric properties of piezoelectric materials [46].

Experimental investigations provide clues that explain the importance of the physicochemical aspects involved in the observed piezoelectric activity in organic materials, elucidate how these are integrated into biological processes, and 
provide a route for exploiting such materials in applications. Analysis by AFM-PFM has been applied to self-assembled amyloid peptide structures, complementing other techniques, to characterize at the nanoscale the molecular building blocks ( $\mathrm{A} \beta$, the amyloid peptide) and the formation and characterization of the fibril and further macromolecular assemblies.

\section{Electromechanical Properties}

Electromechanical activity has been observed in FF peptide structures [8] [9]; however, it is necessary to understand the role of the molecular building blocks themselves on the existence of said activity, in order to i) determine possible peptide-peptide interactions, ii) investigate the use of other organic surfactants for further self-assembly in tubular structures, and iii) quantify the electromechanical response at the nanoscale. For this purpose, it is not only necessary to evaluate the role of ionic strength or thermal changes on self-assembly, but the addition of other molecules such as lipids, amphipathic molecules in the cell membrane, and amino acids must be assessed [47].

In our view, the interactions between amyloid structures and membrane-related molecules such as lipids and voltage-gated channels might elucidate a biofunctional/structural role of the piezoelectric amyloid structures [28]. The observation of multiple conformational states of amyloid fibrils in tubes and wires from the same polypeptide sequence depending on the environmental features (e.g., $\mathrm{pH})$ makes this hypothesis feasible. Furthermore, recent electrophysiology data has measured amyloid-beta toxicity in neurons, inferring an in vivo electrical sensitivity of amyloid structures [48].

\section{Theoretical Calculations}

In order to determine that organic piezoelectricity is produced when amyloid biomolecules assemble and that its stability under electric fields change, molecular simulations were performed, similar to those carried by Kell, Brünger, Gupta and Bystrov [22] [49] [50] [51]. Differences in molecular arrangements in the amyloid biomolecules in tubular structures [20] and crystalline packing were considered. In this approach, molecular dynamics simulations were performed with a possible crystal considering the most stable conformations of the dipeptides in chiral LL, LD, and DD conformations. For this analysis, different physicochemical conditions of pressure and electric field were employed (Table 1). Since self-assemblies of FF strongly depend on crystal nucleation, an additional study was performed to find the most stable structural conformation. For this purpose, an OPLS Force Field was used in the Hyperchem software [52] to determine the potential energy of the dihedral angle (omega) that forms the peptide bond from $0^{\circ}$ up to $180^{\circ}$ (Figure 3 ). The potential energy minima of the dihedral symmetry reached $-382 \mathrm{kcal} \cdot \mathrm{mol}^{-1}, 148 \mathrm{kcal} \cdot \mathrm{mol}^{-1}$, and $386 \mathrm{kcal} \cdot \mathrm{mol}^{-1}$ for LL, LD, and DD diphenylalanine values, respectively, being the LL chiral dimer is the most stable conformation. Once the most stable molecular configuration 
was determined (using an ab-initio method on the Polypargen platform [53] [54] [55] [56] [57]), the molecule parameters obtained were introduced in the GROMACS software [58] [59] [60] (OPLS-AA [61] [62]), while molecular dynamics was performed in NTP during 5 nanoseconds with and without pulsed electric fields (Figure 3). Then, with this information, it is possible to gain insight into the molecular stability.

More precisely, these results show that the most stable omega dihedral angles are the ones from the LL and DD enantiomers (corresponding to $120^{\circ}$ ) whereas the LD-diphenylalanine has an omega dihedral angle of about $60^{\circ}$. With the structural restrictions of these angles, the dipeptides were geometrically optimized through the Leapfrog integration method (step integrator up to an RMS of 0.01, 2500 steps of $0.001 \mathrm{ps}$ ). Moreover, with the purpose to determine the possible piezoelectric properties at isobaric and isochoric conditions, the molecular dynamics simulations were performed in the dipeptide crystal and with no pulsed

Table 1. Calculation of dipole moments and dielectric constants of diphenylalanine crystals, calculated by NPT molecular dynamics of LL and LD dipeptide using the dihedral angle from $60^{\circ}$.

\begin{tabular}{|c|c|c|c|c|}
\hline Pressure/Electric field pulsed Z & $3 \times 3$ crystal & $5 \times 5$ crystal & $7 \times 7$ crystal & $9 \times 9$ crystal \\
\hline $760 \mathrm{~mm} \mathrm{Hg}$ & $3.74607_{\mathrm{LL}}$ & $4.38325_{\mathrm{LL}}$ & $13.3933_{\mathrm{LL}}$ & $23.3795_{\mathrm{LL}}$ \\
\hline \multirow{3}{*}{$760 \mathrm{~mm} \mathrm{Hg}$} & $2.78112_{\mathrm{LD}}$ & $3.00154_{\mathrm{LD}}$ & $6.94678_{\mathrm{LD}}$ & $1.29688_{\mathrm{LD}}$ \\
\hline & $20.4390_{\mathrm{LL}}$ & $20.0439_{\mathrm{LL}}$ & $19.8710_{\mathrm{LL}}$ & $19.9385_{\mathrm{LL}}$ \\
\hline & $8.27050_{\mathrm{LD}}$ & $8.08310_{\mathrm{LD}}$ & $8.03820_{\mathrm{LD}}$ & $8.20280_{\mathrm{LD}}$ \\
\hline \multirow[t]{4}{*}{$5 \mathrm{~V} \cdot \mathrm{nm}^{-1}$} & $5.000985_{\mathrm{LL}}$ & $2.47747_{\mathrm{LL}}$ & $2.79798_{\mathrm{LL}}$ & $4.00701_{\mathrm{LL}}$ \\
\hline & $2.49856 \mathrm{LD}$ & $2.05219_{\mathrm{LD}}$ & $7.88489 \mathrm{LD}$ & $25.5841_{\mathrm{LD}}$ \\
\hline & $20.8982_{\mathrm{LL}}$ & $19.8585_{\mathrm{LL}}$ & $19.8533_{\mathrm{LL}}$ & $20.0747_{\mathrm{LL}}$ \\
\hline & $8.42840_{\mathrm{LD}}$ & $8.0507_{\mathrm{LD}}$ & $8.15980_{\mathrm{LD}}$ & $8.2554_{\mathrm{LD}}$ \\
\hline
\end{tabular}

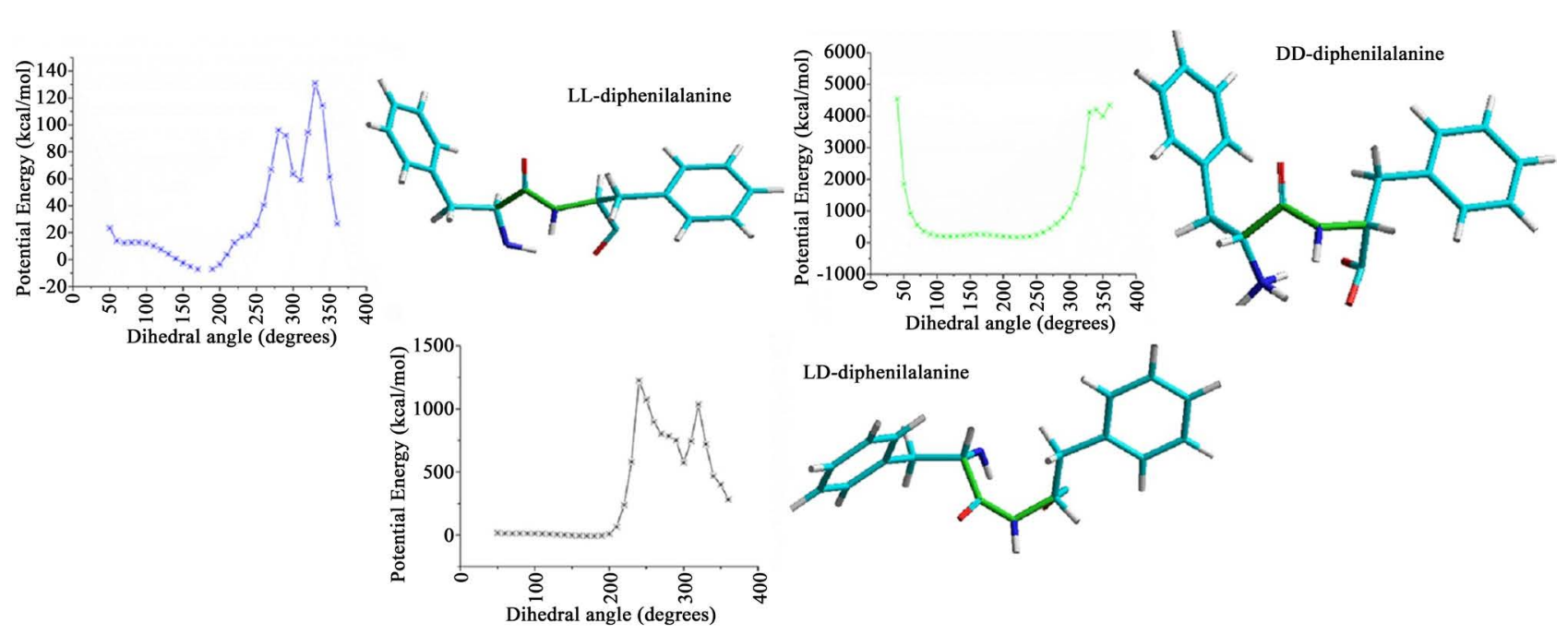

Figure 3. Calculation from potential energy twisting omega dihedral angle considering the most stable conformation for the diphenylalanine (FF) dipeptides. Left, LL-diphenylalanine, center, LD-diphenylalanine and right, DD-diphenylalanine. 
electric field. Both simulations were compared to determine the possible molecular displacement of the crystals via electric field; these results are displayed in Table 1).

In the case of LL-diphenylalanine, it is noticeable that the data distribution function (epsilon value) decreases in the presence of a pulsed electric field, i.e. the dipole-dipole interaction is weaker, suggesting a dissociation between the dipoles of the peptides. It is caused by a change in the dimensions by expansion of the crystal slab when an electric field of $5 \mathrm{~V} \cdot \mathrm{nm}^{-1}$ is applied. On the other hand, in the case of LD-diphenylalanine, since it presents a dihedral angle of less than $60^{\circ}$ (Figure 3 ), the aromatic rings separate the neighboring molecules, and therefore the value of epsilon is 5 times smaller than that of the LL molecules (Table 1). This fact is also reflected in the dipole moment of the LD crystal since the random interactions in their positions in the dynamics decrease this value drastically compared to those calculated from the LL crystal. The electric field does not significantly modify the parameters epsilon and dipole moment. Additionally, with the minimized energy conformation of crystals, 5 ns NPT dynamics were performed with the OPLS-AA force system for pressures that exist in a human body with pressure around $60-100 \mathrm{mmHg}$ and $110-150 \mathrm{mmHg}$, resulting in variations of the average dipole moment values of the crystal and in the epsilon with respect to the pressure, whose results are shown below for the dipeptides.

Considering the simulations in the LL and LD crystals, the molecular dynamics rendered relevant results when the models were subjected to the mentioned pressures (Figure 4). The variation in pressure (Figure 4) refers to the interaction of a dipole with its neighboring dipole, presenting a tendency to align itself by increasing the initial crystal size from $5 \mathrm{~nm}$ per edge to $7 \mathrm{~nm}$ per edge. Moreover, if the edge size continues to increase up to $9 \mathrm{~nm}$, the parameter epsilon presents a decrease; therefore, there is a maximum for which these dipole-dipole interactions are relevant in the crystal behavior. Pressure variations
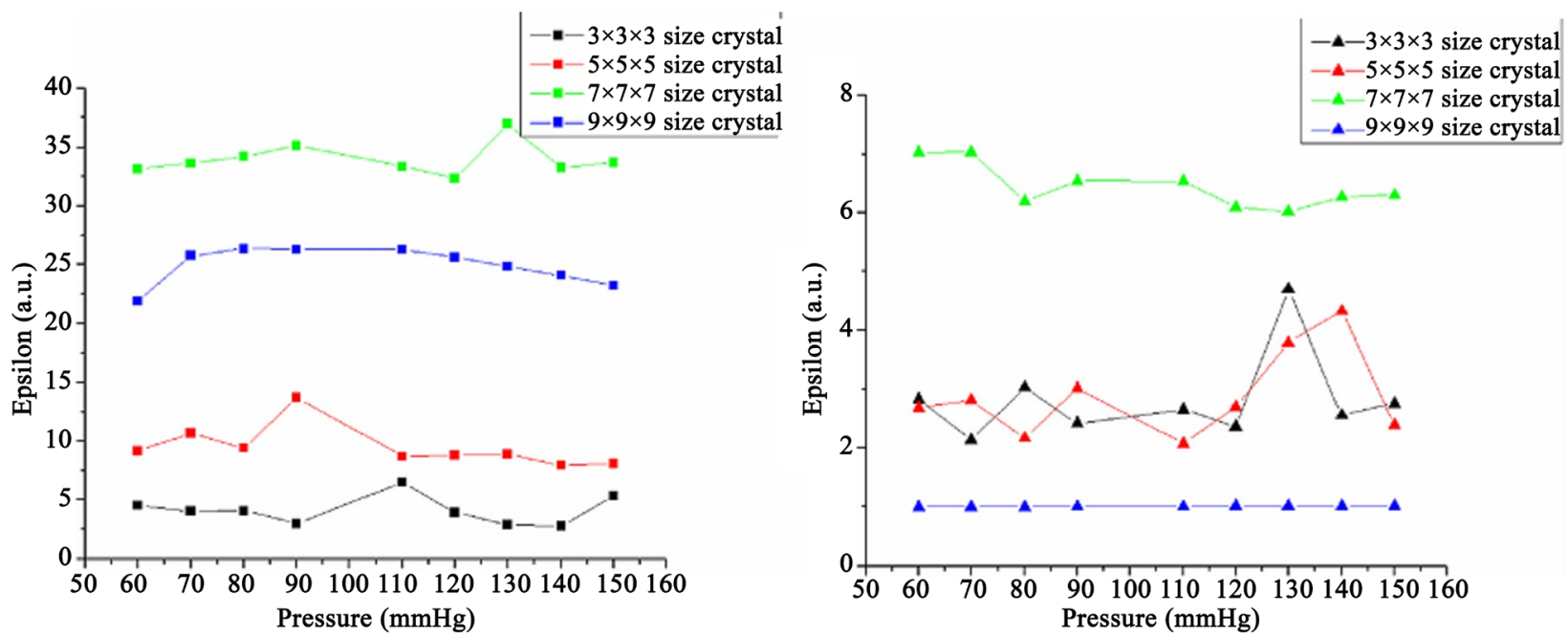

Figure 4. Epsilon behavior of (left) LL and (right) LD dipeptide crystals as a function of pressure. 

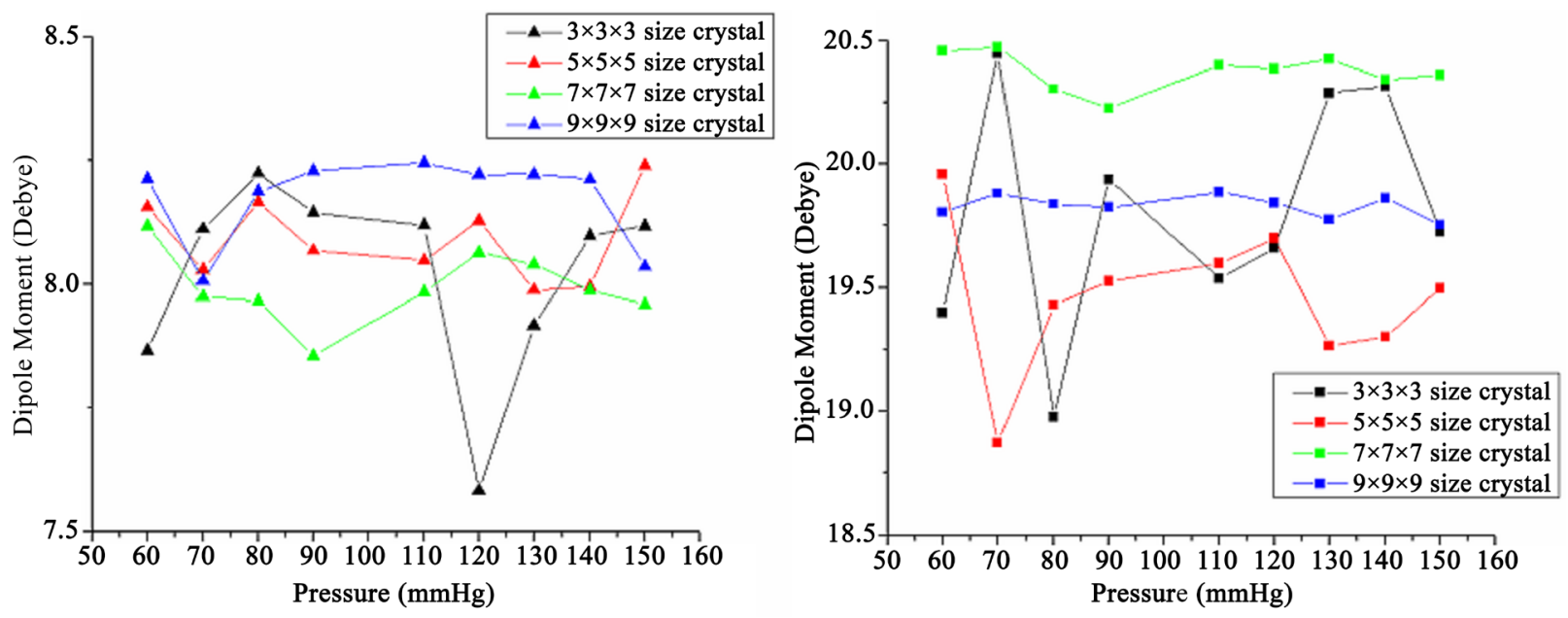

Figure 5. Dipole moments from the simulations (left) LD and (right) LL crystal as a function of pressure.

increase the dipolar moment average in LD crystals of $5 \times 5 \times 5$ and $7 \times 7 \times 7 \mathrm{~nm}$ of edge, at a pressure of $120 \mathrm{~mm} \mathrm{Hg}$ corroborate that in these conditions there is a high dipolar moment average due to the alignment of most dipoles in one direction. For LL crystals the piezoelectric behavior presents variations in pressure of $130 \mathrm{~mm} \mathrm{Hg}$ in the crystals of $3 \times 3 \times 3$ to $9 \times 9 \times 9 \mathrm{~nm}$ of edge, Figure 5 .

\section{Conclusion}

The success of the electromechanical studies allows identifying inhibitors or controllers of the amyloid self-assembly process. Therefore, for the purpose of improving the electromechanical properties, it is necessary to: study the solvent-peptide interactions by tuning the ion strength and thermal conditions during assembly; quantify the electromechanical activity in self-assembled structures; and determine the role of intramolecular forces (arising from the presence of water) on piezoelectricity and mechanism of piezoelectricity and its possible role in amyloid stability as well as the nanoscale structure in different directions (i.e., cross-section, surface) of the amyloid structures; and develop the framework to exploit electromechanical coupling in amyloid-based structures for nano-bio technologies, such as piezoelectric biosensors.

\section{Acknowledgements}

The authors thank M.Sc. Luciano Díaz González, Martín Cruz Villafañe, Luis Miguel Valdez Pérez, Ing. Juan Eduardo Murrieta León, Antonio Ramírez Fernández, and Enrique Palacios Boneta for their technical assistance. We also thank Homero Heredia Barbero for the design of some parts of this manuscript. This research was funded by the Programa de Apoyo a Proyectos de Investigación e InnovaciónTecnológica PAPIIT UNAM Project IN210119.

\section{Conflicts of Interest}

The authors declare no conflicts of interest regarding the publication of this pa- 
per.

\section{References}

[1] McGowan, D.P., van Roon-Mom, W., Holloway, H., Bates, G.P., Mangiarini, L., Cooper, G.J.S., Faull, R.L.M. and Snell, R.G. (2000) Amyloid-Like Inclusions in Huntington's Disease. Neuroscience, 100, 677-680.

https://doi.org/10.1016/S0306-4522(00)00391-2

[2] Gu, L. and Guo, Z.F. (2013) Alzheimer's A $\beta 42$ and $A \beta 40$ Peptides form Interlaced Amyloid Fibrils. Journal of Neurochemistry, 126, 305-311. https://doi.org/10.1111/jnc.12202

[3] Grimm, M.O.W., Grimm, H.S. and Hartmann, T. (2007) Amyloid Beta as a Regulator of Lipid Homeostasis. Trends in Molecular Medicine, 13, 337-344. https://doi.org/10.1016/j.molmed.2007.06.004

[4] Cölfen, H. and Mann, S. (2003) Higher-Order Organization by Mesoscale Self- Assembly and Transformation of Hybrid Nanostructures. Angewandte Chemie International Edition, 42, 2350-2365. https://doi.org/10.1002/anie.200200562

[5] Kerrigan, T.L., Atkinson, L., Peers, C. and Pearson, H.A. (2008) Modulation of 'A'-Type $\mathrm{K}^{+}$Current by Rodent and Human Forms of Amyloid $\beta$ Protein. NeuroReport, 19, 839-843. https://doi.org/10.1097/WNR.0b013e3282ff636b

[6] Scragg, J.L., Fearon, I.M., Boyle, J.P., Ball, S.G., Varadi, G. and Peers, C. (2005) Alzheimer's Amyloid Peptides Mediate Hypoxic Up-Regulation of L-Type $\mathrm{Ca}^{2+} \mathrm{Chan}-$ nels. The FASEB Journal, 19, 150-152. https://doi.org/10.1096/fj.04-2659fje

[7] Castelletto, V., Hamley, I.W. and Harris, P.J.F. (2008) Self-Assembly in Aqueous Solution of a Modified Amyloid Beta Peptide Fragment. Biophysical Chemistry, 138, 29-35. https://doi.org/10.1016/j.bpc.2008.08.007

[8] Heredia, A., Bdikin, I., Kopyl, S., Mishina, E., Semin, S., Sigov, A., German, K., Bystrov, V., Gracio, J. and Kholkin, A.L. (2010) Temperature-Driven Phase Transformation in Self-Assembled Diphenylalanine Peptide Nanotubes. Journal of Physics D: Applied Physics, 43, Article ID: 462001. https://doi.org/10.1088/0022-3727/43/46/462001

[9] Kholkin, A., Amdursky, N., Bdikin, I., Gazit, E. and Rosenman, G. (2010) Strong Piezoelectricity in Bioinspired Peptide Nanotubes. ACS Nano, 4, 610-614. https://doi.org/10.1021/nn901327v

[10] Kol, N., Adler-Abramovich, L., Barlam, D., Shneck, R.Z., Gazit, E. and Rousso, I. (2005) Self-Assembled Peptide Nanotubes are Uniquely Rigid Bioinspired Supramolecular Structures. Nano Letters, 5, 1343-1346. https://doi.org/10.1021/nl0505896

[11] Niu, L., Chen, X., Allen, S. and Tendler, S.J.B. (2007) Using the Bending Beam Model to Estimate the Elasticity of Diphenylalanine Nanotubes. Langmuir, 23, 7443-7446. https://doi.org/10.1021/la7010106

[12] Mann, S. (2009) Self-Assembly and Transformation of Hybrid Nano-Objects and Nanostructures under Equilibrium and Non-Equilibrium Conditions. Nature Materials, 8, 781-792. https://doi.org/10.1038/nmat2496

[13] Adler-Abramovich, L., Aronov, D., Beker, P., Yevnin, M., Stempler, S., Buzhansky, L., Rosenman, G. and Gazit, E. (2009) Self-Assembled Arrays of Peptide Nanotubes by Vapour Deposition. Nature Nanotechnology, 4, 849-854. https://doi.org/10.1038/nnano.2009.298

[14] Mann, S., Archibald, D.D., Didymus, J.M., Douglas, T., Heywood, B.R., Meldrum, 
F.C. and Reeves, N.J. (1993) Crystallization at Inorganic-Organic Interfaces: Biominerals and Biomimetic Synthesis. Science, 261, 1286-1292. https://doi.org/10.1126/science.261.5126.1286

[15] Gazit, E. (2002) A Possible Role for $\pi$-Stacking in the Self-Assembly of Amyloid Fibrils. The FASEB Journal, 16, 77-83. https://doi.org/10.1096/fj.01-0442hyp

[16] Görbitz, C.H. (2001) Nanotube Formation by Hydrophobic Dipeptides. Chemistry-A European Journal, 7, 5153-5159.

https://doi.org/10.1002/1521-3765(20011203)7:23<5153::AID-CHEM5153>3.0.CO;2 $\underline{-\mathrm{N}}$

[17] Wang, M.J., Du, L.J., Wu, X.L., Xiong, S.J. and Chu, P.K. (2011) Charged Diphenylalanine Nanotubes and Controlled Hierarchical Self-Assembly. ACS Nano, 5, 4448-4454. https://doi.org/10.1021/nn2016524

[18] Perriman, A.W., Brogan, A.P.S., Cölfen, H., Tsoureas, N., Owen, G.R. and Mann, S. (2010) Reversible Dioxygen Binding in Solvent-Free Liquid Myoglobin. Nature Chemistry, 2, 622-626. https://doi.org/10.1038/nchem.700

[19] Huang, R.L., Su, R.X., Qi, W., Zhao, J. and He, Z.M. (2011) Hierarchical, Interface-Induced Self-Assembly of Diphenylalanine: Formation of Peptide Nanofibers and Microvesicles. Nanotechnology, 22, Article ID: 245609. https://doi.org/10.1088/0957-4484/22/24/245609

[20] Reches, M. and Gazit, E. (2003) Casting Metal Nanowires within Discrete Self- Assembled Peptide Nanotubes. Science, 300, 625-627.

https://doi.org/10.1126/science.1082387

[21] Reches, M. and Gazit, E. (2006) Controlled Patterning of Aligned Self-Assembled Peptide Nanotubes. Nature Nanotechnology, 1, 195-200. https://doi.org/10.1038/nnano.2006.139

[22] Kelly, C.M., Northey, T., Ryan, K., Brooks, B.R., Kholkin, A.L., Rodriguez, B.J. and Buchete, N.V. (2015) Conformational Dynamics and Aggregation Behavior of Piezoelectric Diphenylalanine Peptides in an External Electric Field. Biophysical Chemistry, 196, 16-24. https://doi.org/10.1016/j.bpc.2014.08.009

[23] Walsh, D.M., Lomakin, A., Benedek, G.B., Condron, M.M. and Teplow, D.B. (1997) Amyloid $\beta$-Protein Fibrillogenesis: Detection of a Protofibrillar Intermediate. Journal of Biological Chemistry, 272, 22364-22372. https://doi.org/10.1074/jbc.272.35.22364

[24] Yuan, J.H., Chen, J.R., Wu, X.H., Fang, K.M. and Niu, L. (2011) A NADH Biosensor Based on Diphenylalanine Peptide/Carbon Nanotube Nanocomposite. Journal of Electroanalytical Chemistry, 656, 120-124. https://doi.org/10.1016/j.jelechem.2010.12.018

[25] Morgan, C., Colombres, M., Nuñez, M.T. and Inestrosa, N.C. (2004) Structure and Function of Amyloid in Alzheimer's Disease. Progress in Neurobiology, 74, 323-349. https://doi.org/10.1016/j.pneurobio.2004.10.004

[26] Kim, J.B, Han, T.H., Kim, Y.I., Park, J.S., Choi, J.W., Churchill, D.G., Kim, S.O. and Ihee, H. (2010) Role of Water in Directing Diphenylalanine Assembly into Nanotubes and Nanowires. Advance Materials, 22, 583-587.

https://doi.org/10.1002/adma.200901973

[27] Mori, H., Takio, K., Ogawarag, M. and Selkoen, D.J. (1992) Mass Spectrometry of Purified Amyloid Beta Protein in Alzheimer's Disease. Journal of Biological Chemistry, 267, 17082-17086. https://www.jbc.org/content/267/24/17082.short

[28] Schmidt, M., Sachse, C., Richter, W., Xu, C., Fändrich, M. and Grigorieff, N. (2009) 
Comparison of Alzheimer $\mathrm{A} \beta(1-40)$ and $\mathrm{A} \beta(1-42)$ Amyloid Fibrils Reveals Similar Protofilament Structures. Proceedings of the National Academy of Sciences of the United States of America, 106, 19813-19818. https://doi.org/10.1073/pnas.0905007106

[29] Perutz, M.F., Finch, J.T., Berriman, J. and Lesk, A. (2002) Amyloid Fibers Are Water-Filled Nanotubes. Proceedings of the National Academy of Sciences of the United States of America, 99, 5591-5595. https://doi.org/10.1073/pnas.042681399

[30] Widenbrant, M.J.O., Rajadas, J., Sutardja, C. and Fuller, G.G. (2006) Lipid-Induced $\beta$-Amyloid Peptide Assemblage Fragmentation. Biophysical Journal, 91, 4071-4080. https://doi.org/10.1529/biophysj.106.085944

[31] Ryan, K., Beirne, J., Redmond, G., Kilpatrick, J.I., Guyonnet, J., Buchete, N.V., Kholkin, A.L. and Rodriguez, B.J. (2015) Nanoscale Piezoelectric Properties of Self-Assembled Fmoc-FF Peptide Fibrous Networks. ACS Applied Materials \& Interfaces, 7, 12702-12707. https://doi.org/10.1021/acsami.5b01251

[32] Nie, Q., Du, X.G. and Geng, M.Y. (2011) Small Molecule Inhibitors of Amyloid $\beta$ Peptide Aggregation as a Potential Therapeutic Strategy for Alzheimer's Disease. Acta Pharmacologica Sinica, 32, 545-551. https://doi.org/10.1038/aps.2011.14

[33] Nikiforov, M.P., Thompson, G.L., Reukov, V.V., Jesse, S., Guo, S., Rodriguez, B.J., Seal, K., Vertegel, A.A. and Kalinin, S.V. (2010) Double-Layer Mediated Electromechanical Response of Amyloid Fibrils in Liquid Environment. ACS Nano, 4, 689-698. https://doi.org/10.1021/nn901127k

[34] Tuszynski, J.A., John, T., Craddock, A. and Carpenter, E.J. (2008) Bio-Ferroelectricity at the Nanoscale Bio-Ferroelectricity at the Nanoscale. Journal of Computational and Theoretical Nanoscience, 5, 2022-2032.

https://doi.org/10.1166/jctn.2008.1008

[35] Heredia, A., Bui, C.C., Suter, U., Young, P. and Schäffer, T.E. (2007) AFM Combines Functional and Morphological Analysis of Peripheral Myelinated and Demyelinated Nerve Fibers. Neuroimage, 37, 1218-1226.

https://doi.org/10.1016/j.neuroimage.2007.06.007

[36] Heredia, A., Bdikin, I., Baltazar, G. and Kholkin, A. (2010) Ferroelectric Properties of Dried Rat Embryonic Neurons from the Substantia Nigra by the Piezoresponse Force Microscopy. European Cells and Materials, 20, 292.

http://www.scopus.com/inward/record.url?eid=2-s2.0-84860891306\&partnerID=M N8TOARS

[37] Heredia, A., Machado, M., Bdikin, I.K., Gracio, J., Yudin, S., Fridkin, V.M., Delgadillo, I. and Kholkin, A.L. (2010) Preferred Deposition of Phospholipids onto Ferroelectric P(VDF-TrFE) Films via Polarization Patterning. Journal of Physics D: Applied Physics, 43, Article ID: 335301. https://doi.org/10.1088/0022-3727/43/33/335301

[38] Kühnle, A. (2009) Self-Assembly of Organic Molecules at Metal Surfaces. Current Opinion in Colloid \& Interface Science, 14, 157-168. https://doi.org/10.1016/j.cocis.2008.01.001

[39] Lu, K., Jacob, J., Thiyagarajan, P., Conticello, V.P. and Lynn, D.G. (2003) Exploiting Amyloid Pibril Lamination for Nanotube Self-Assembly. Journal of the American Chemical Society, 125, 6391-6393. https://doi.org/10.1021/ja0341642

[40] Meinhardt, J., Sachse, C., Hortschansky, P., Grigorieff, N. and Fändrich, M. (2009) A $\beta(1-40)$ Fibril Polymorphism Implies Diverse Interaction Patterns in Amyloid Fibrils. Journal of Molecular Biology, 386, 869-877.

https://doi.org/10.1016/j.jmb.2008.11.005 
[41] Faller, P., Hureau, C. and Berthoumieu, O. (2013) Role of Metal Ions in the Self-Assembly of the Alzheimer's Amyloid- $\beta$ Peptide. Inorganic Chemistry, 52, 12193-12206. https://doi.org/10.1021/ic4003059

[42] Huang, R.L., Wang, Y.F., Qi, W., Su, R.X. and He, Z.M. (2014) Temperature-Induced Reversible Self-Assembly of Diphenylalanine Peptide and the Structural Transition from Organogel to Crystalline Nanowires. Nanoscale Research Letters, 9, Article No. 653. https://doi.org/10.1186/1556-276X-9-653

[43] Kalinin, S.V., Rodriguez, B.J., Jesse, S., Thundat, T. and Gruverman, A. (2005) Electromechanical Imaging of Biological Systems with Sub-10nm Resolution. Applied Physics Letters, 87, Article ID: 053901. https://doi.org/10.1063/1.2006984

[44] Zandomeneghi, G., Krebs, M.R.H., McCammon, M.G. and Fändrich, M. (2009) FTIR Reveals Structural Differences between Native $\beta$-Sheet Proteins and Amyloid Fibrils. Protein Science, 13, 3314-3321. https://doi.org/10.1110/ps.041024904

[45] Dave, N., Lórenz-Fonfría, V.A., Leblanc, G. and Padrós, E. (2008) FTIR Spectroscopy of Secondary-Structure Reorientation of Melibiose Permease Modulated by Substrate Binding. Biophysical Journal, 94, 3659-3670.

https://doi.org/10.1529/biophysj.107.115550

[46] Nguyen, V., Zhu, R., Jenkins, K. and Yang, R. (2016) Self-Assembly of Diphenylalanine Peptide with Controlled Polarization for Power Generation. Nature Communications, 7, Article No. 13566. https://doi.org/10.1038/ncomms13566

[47] Wetzel, R., Shivaprasad, S. and Williams, A.D. (2007) Plasticity of Amyloid Fibrils. Biochemistry, 46, 1-10. https://doi.org/10.1021/bi0620959

[48] Varghese, K., Molnar, P., Das, M., Bhargava, N., Lambert, S., Kindy, M.S. and Hickman, J.J. (2010) A New Target for Amyloid Beta Toxicity Validated by Standard and High-Throughput Electrophysiology. PLoS ONE, 5, e8643. https://doi.org/10.1371/journal.pone.0008643

[49] Brünger, A., kuriyan, J and karplus, M. (1987) Crystallographic R Factor Refinement by Molecular Dynamics. Science, 235, 458-460. https://doi.org/10.1126/science.235.4787.458

[50] Gupta, V. P. (2016) 12-Characterization of Chemical Reactions. In: Gupta, V.P., Ed., Principles and Applications of Quantum Chemistry, Academic Press, San Diego, 385-433. https://doi.org/10.1016/B978-0-12-803478-1.00012-1

[51] Bystrov, V.S., Zelenovskiy, P.S., Nuraeva, A.S., Kopyl, S. and Zhulyabina, O.A. (2019) Molecular Modeling and Computational Study of the Chiral-Dependent Structures and Properties of Self-Assembling Diphenylalanine Peptide Nanotubes. Journal of Molecular Modeling, 25, Article No. 199. https://doi.org/10.1007/s00894-019-4080-x

[52] Hypercube, Inc. (2003) HyperChem ${ }^{\mathrm{TM}}$ Professional 7.51. Hypercube, Inc., Gainesville.

[53] Dodda, L.S., Cabeza de Vaca, I., Tirado-Rives, J. and Jorgensen, W.L. (2017) LigParGen web Server: An Automatic OPLS-AA Parameter Generator for Organic Ligands. Nucleic Acids Research, 45, W331-W336. https://doi.org/10.1093/nar/gkx312

[54] Jorgensen, W.L. and Tirado-Rives, J. (2005) Molecular Modeling of Organic and Biomolecular Systems Using BOSS and MCPRO. Journal of Computational Chemistry, 26, 1689-1700. https://doi.org/10.1002/jcc.20297

[55] Yabe, M., Mori, K., Ueda, K. and Takeda, M. (2019). Development of PolyParGen Software to Facilitate the Determination of Molecular Dynamics Simulation Parameters for Polymers. Journal of Computer Chemistry, Japan-International Edition, 
5, 1-5. https://doi.org/10.2477/jccjie.2018-0034

[56] Wang, J., Wang, W., Kollman, P.A. and Case, D.A. (2006) Automatic Atom Type and Bond Type Perception in Molecular Mechanical Calculations. Journal of Molecular Graphics and Modelling, 25, 247-260.

https://doi.org/10.1016/j.jmgm.2005.12.005

[57] Sousa Da Silva, A.W. and Vranken, W.F. (2012) ACPYPE-AnteChamber PYthon Parser interfacE. BMC Research Notes, 5, Article No. 367. https://doi.org/10.1186/1756-0500-5-367

[58] Lindahl, E., Abraham, M.J., Hess, B. and van der Spoel, D. (2019) GROMACS 2019.4 Source Code. https://doi.org/10.5281/zenodo.3460414

[59] Kutzner, C., Páll, S., Fechner, M., Esztermann, A., de Groot, B.L. and Grubmüller, H. (2019) More Bang for Your Buck: Improved Use of GPU Nodes for GROMACS 2018. Journal of Computational Chemistry, 40, 2418-2431. https://doi.org/10.1002/jcc.26011

[60] Kutzner, C., Páll, S., Fechner, M., Esztermann, A., de Groot, B.L. and Grubmüller, H. (2015) Best Bang for Your Buck: GPU Nodes for GROMACS Biomolecular Simulations. Journal of Computational Chemistry, 36, 1990-2008.

https://doi.org/10.1002/jcc.24030

[61] Kilpeläinen, T., Shahgholian, H. and Zhong, X. (2007) Growth Estimates Through Scaling for Quasilinear Partial Differential Equations. Annales Academiae Scientiarum Fennicae: Mathematica, 32, 595-599.

http://www.acadsci.fi/mathematica/Vol32/vol32pp595-599.pdf

[62] Jorgensen, W.L., Maxwell, D.S. and Tirado-Rives, J. (1996) Development and Testing of the OPLS All-Atom Force Field on Conformational Energetics and Properties of Organic Liquids. Journal of the American Chemical Society, 118, 11225-11236. https://doi.org/10.1021/ja9621760 